\title{
The Corrections of Codex Sinaiticus and the Textual Transmission of Revelation: Josef Schmid Revisited"
}

\author{
Peter Malik \\ University of Cambridge \\ Faculty of Divinity \\ West Road, Cambridge CB3 9BS \\ United Kingdom \\ pm486@cam.ac.uk
}

\section{Abstract}

The role of manuscript corrections in studying textual transmission of the New Testament has been long recognised by textual critics. And yet, the actual witness of corrections may at times be difficult to interpret. A case in point is Josef Schmid's seminal work on the text of Revelation. Following Wilhelm Bousset, Schmid argued that a particular group of corrections in Codex Sinaiticus reflected a Vorlage with a text akin to that of the Andreas text-type. By dating these corrections unlike Bousset - to the scriptorium, Schmid utilised their witness to trace the text of Andreas back to the fourth century. Recently, Juan Hernández has shown that the corrections cited by Schmid were significantly later, hence calling his fourth-century dating of Andreas (among other things) into question. Through an analysis of the corrections cited by Schmid, supplemented by a fuller data-set of Sinaiticus' corrections in Revelation, this study seeks to reappraise Schmid's claims concerning the textual relations of these corrections, and identify their role in the later transmission of the text of Revelation.

\footnotetext{
* I would like to thank Juan Hernández Jr. and the anonymous reviewer for their careful reading of an earlier draft of this article, as well as their helpful comments and corrections. All the remaining shortcomings are my own.
} 
Keywords: Codex Sinaiticus, manuscript corrections, Apocalypse, Josef Schmid, transmission history

1. Introductory Remarks: Schmid, Hernández, and Beyond

In Josef Schmid's influential study of the textual history of Revelation, Codex Sinaiticus figures prominently as the main (and the only complete) representative of one of the two early textforms. Unlike the superior text-form attested by the codices Alexandrinus and Ephraemi, as well as the text of Oecumenius' commentary, the one attested by Sinaiticus, $\mathfrak{P}^{47}$ and Origen already contains a fair number of improvements ("Korrekturen") to the "original text."' Sinaiticus was probably produced around the middle of the fourth century (or possibly earlier), ${ }^{2}$ so Schmid's claim that, already in the fourth century, the text of Revelation in Sinaiticus was corrected towards another textform, known from the later commentary of Andreas, is remarkable. Now, the fact that a number of Sinaiticus' corrections reflect a Vorlage akin to the Andreas text was not Schmid's discovery. Rather, Schmid builds on an earlier work of W. Bousset, who had identified a number of corrections related to what is now referred to as the Andreas tradition. ${ }^{3}$ Significantly, Schmid reinterprets

\footnotetext{
${ }^{1}$ See J. Schmid, Studien zur Geschichte des griechischen Apokalypse-Textes, Teil 1: Der Apokalypse-Kommentar des Andreas von Kaisareia, Band 1: Text, Band 2: Einleitung, Teil 2: Die alten Stämme (Münchener theologische Studien 4; Munich: Karl Zink, 1955-1956), 2.147.

${ }^{2}$ Cf. D.C. Parker, Codex Sinaiticus: The Story of the World's Oldest Bible (London and Peabody: British Library and Hendrickson, 2010), 7, who suggests a date at "[a]round the middle of the fourth century." Conversely H.J.M. Milne and T.C. Skeat, Scribes and Correctors of the Codex Sinaiticus (London: British Museum, 1938), 61-62, suggest the first half of the fourth century.

${ }^{3}$ W. Bousset, "Zur Textkritik der Apokalypse," in Textkritische Studien zum Neuen Testament (TU 2.4; Leipzig: Hinrichs, 1894), 1-44 (esp. 42-44). See also J. Hernández, Jr., "The Creation of a Fourth-Century Witness to the Andreas Text Type: A Misreading in the Apocalypse's Textual History," NTS (2014), 109. A thorough reappraisal of Bousset's theories has been recently undertaken in J. Hernández Jr., "The Legacy of Wilhelm Bousset for the Apocalypse's Textual History: The Identification of the Andreas Text," in Studien zum Text der Apokalypse, ed. M. Sigismund, M. Karrer, and U. Schmid (ANTF; Berlin and New York: De Gruyter, forthcoming). Note that Bousset does not explicitly align the corrected readings of Sinaiticus with Andreas, but rather with $K$, the archetype of the text of Revelation that is preserved in the text of Andreas' commentary. See further Hernández Jr., "The Legacy of Wilhelm Bousset," 22-23; Hernández, "Creation," 110 n. 19.
} 
Bousset's conclusions in light of H.J.M. Milne and T.C. Skeat's investigation of scribes and correctors in Sinaiticus, ${ }^{4}$ identifying Bousset's (and Tischendorf's) seventh-century $\aleph^{c}$ corrections with scribal corrections made in the scriptorium, some three centuries earlier. Thus, Schmid concluded that "Bousset zu dem klaren und sicheren Ergebnis gelangt, daß wenigstens der überwiegende Teil der aus dem 4.Jh. stammenden Korrekturen $\left(=\mathrm{S}^{\mathrm{a}}\right)$ einer zu $A \nu$ gehörenden Hs entnommen wurde." ${ }^{5}$ But Bousset never reached such a conclusion. In fact, Juan Hernández has recently shown ${ }^{6}$ that, unlike Schmid, Bousset never makes fourth-century claims with respect to these corrections, but simply follows Tischendorf, who dated the C-class corrections to the seventh century. ${ }^{7}$ Schmid's fourth-century dating, argues Hernández, seems to stem from his misreading of Milne and Skeat precisely the authority to which Schmid appeals in re-dating the corrections. ${ }^{8}$

Such a confusion has, naturally, some implications, and Hernández spells out the following: Every occurrence of $S^{a}$ must now be read in light of its re-established seventh-century status. The alignment of $S^{\text {a }}$ to particular witnesses is unlikely to change in most, if not all, cases; the conception of it as a fourth-century witness will change in every case. The most consequential revisions will occur where $S^{a}$ is marshalled in support of a fourth-century date for the Andreas text type ... The impact on other parts of Schmid's work will vary commensurate with the arguments advanced for particular cases. Again, textual realignments are unlikely, but the evidentiary weight of $S^{a}$ will shift. Its value as a witness ... will fluctuate on a case-by-case basis. The textual history of select

\footnotetext{
${ }^{4}$ Milne and Skeat, Scribes and Correctors.

${ }^{5}$ Schmid, Studien, 2.127 .

${ }^{6}$ Hernández, "Creation” (esp. 109-110).

${ }^{7}$ Cf. Bousset, "Textkritik," 42; C. Tischendorf, ed., Novum Testamentum Graece, vol. 1-2, (8th ed.; trans. J. C. Hinrichs; 1894; 8th ed.; Leipzig: Giesecke and Devrient, 1869-1872, vol. 3: Prolegomena (scripsit C.R. Gregory; Leipzig: J.C. Hinrichs, 1894), 3.346.

${ }^{8}$ Hernández, “Creation," 110-113.
} 
readings will also appear in a new light ... The current investigation will also inform contemporary discussions over text types.

Hernández is correct in identifying a serious dating error in Schmid's argument, and Sinaiticus' many corrections to the text of Revelation definitely warrant reinvestigation. ${ }^{9}$ However, his claim of a seventh-century date for Schmid's $S^{\text {a }}$ corrections may appear, in this article at least, overconfident. Indeed, Milne and Skeat were themselves hesitant to ascribe a definitive date to the C-class corrections, allowing for some leeway anywhere between the fifth- and seventh-century dates. ${ }^{10}$ Later on, Skeat would give a more specific judgement concerning the $\mathrm{C}^{\mathrm{a}}$ corrector in particular, dating him to the sixth century. ${ }^{\text {II }}$ More recently still, Amy C. Myshrall's palaeographical analysis led her to similar conclusions. ${ }^{12}$ And even in his latest article, Hernández has invoked Milne and Skeat's more cautious stance, calling for fresh palaeographical investigations. ${ }^{13}$ If indeed $\mathrm{C}^{\mathrm{a}}$ worked in (roughly) sixth century, then his corrections still predate, by almost a century, the composition of Andreas' commentary, not to mention later minuscules with the Andreas-type text. Since the text of $\mathrm{C}^{\text {as }}$ exemplar must have predated his correcting activity, it could theoretically still be viewed as a sixth-century - and possibly even earlier - witness to the Andreas text. The dating of these corrections, however, cannot, as such, settle the matter. Indeed, as will be seen, further com-

\footnotetext{
${ }^{9}$ The earliest layer of corrections in Revelation is a subject of my forthcoming study. On the earliest corrections of the Marcan portion, see my "The Earliest Corrections in Codex Sinaiticus: A Test Case from the Gospel of Mark," BASP 50 (2013): 207-254.

${ }^{10}$ Milne and Skeat, Scribes and Correctors, 65.

${ }^{11}$ T.C. Skeat, "The Codex Sinaiticus, The Codex Vaticanus and Constantine," in Collected Biblical Writings of T.C. Skeat (Introduced and edited by J. K. Elliott; NovTSup 113; Leiden: Brill, 2004), 200.

${ }^{12}$ Cf. A.C. Myshrall, "Codex Sinaiticus, its Correctors, and the Caesarean Text of the Gospels” (Ph.D. diss., University of Birmingham, 2005), 91: "The date suggested by Milne and Skeat as between the $5^{\text {th }}$ and 7 th centuries can thus be seen as reasonable, although I would tend to place $\mathrm{C}^{\text {a }}$ towards the first half of this period."

${ }^{13}$ See Hernández Jr., "The Legacy of Wilhelm Bousset," $3^{0-31} \mathrm{nn} .5^{0-51}$. Incidentally, NA ${ }^{28}$ continues to date these corrections (designated as $\aleph^{2}$ ) to the seventh century. Cf. Hernández, "Creation," 116, 118-119.
} 
plexities are involved in this line of enquiry, complexities which must be dealt with on a case-bycase basis.

\section{2. $S^{a}$ Corrections: Analysis ${ }^{14}$}

In what follows, then, we shall inspect all the $S^{a}$ corrections cited by Schmid, enquiring into their origin and textual significance. The results of our analysis shall be reflected upon in the final section.

As for the presentation, the readings are grouped according to sections of Schmid's work wherein they appear. It will occasionally be observed that Schmid only cites one part of a larger correction and even divides it into several variation-units. Since such a procedure is not without problems, both the initial and the corrected readings are listed in their entirety, with Schmid's delineation of variation-units underlined. ${ }^{15}$ The corrected reading is, at each point, preceded by a siglum indicating the corrector. Unless otherwise noted, the readings of Sinaiticus and identifications of correctors are derived from the Codex Sinaiticus Project (CSP) website ${ }^{16}$ while the textual evidence cited comes primarily from $\mathrm{NA}^{27-28}$, supplemented (where appropriate) by Lembke's collation of $2846^{17}$ and Hoskier's edition. ${ }^{18}$

\footnotetext{
${ }^{14}$ When using the " $\mathrm{S}$ " siglum, I refer to Schmid's manner of citing these corrections rather than my own classification. Note that I exclude corrections listed in Schmid, Studien, 128 n. 2, as they play no role in Schmid's argument.

${ }^{15}$ Cf. E.J. Epp, “Toward the Clarification of the Term “Textual Variant', in Perspectives of New Testament Textual Criticism: Collected Essays, 1962-2004, ed. E. J. Epp (NovTSup 116; Leiden and Boston: Brill, 2005).

${ }^{16}$ www.codexsinaiticus.org.

${ }^{17}$ M. Lembke, "Die Apokalypse-Handschrift 2846: Beschreibung, Kollation und Textwertbestimmung eines wichtigen neuen Zeugen," NovT 54 (2012): 369-395.

${ }^{18}$ H.C. Hoskier, Concerning the Text of the Apocalypse: Collations of All Existing Available Greek Documents with the Standard Text of Stephen's Third Edition, Together with the Testimony of Versions, Commentaries and Fathers. A Complete Conspectus of All Authorities (2 vols.; London: Bernard Quaritch, 1929).
} 


\subsection{Major Textual Groupings}

Schmid lists seven corrections agreeing with the Andreas text: ${ }^{19}$
4.1 $\lambda \varepsilon \gamma \omega \omega \nu$ rell

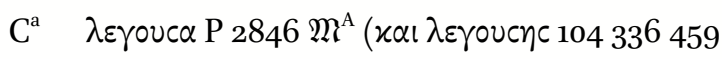 5826286809221918 | om. $\lambda$ Eroucd 20262057 2087)
$7.9 \pi \varepsilon \rho 1 \beta \varepsilon \beta \lambda \eta \mu \varepsilon v 0 u c$ rell $(\pi \varepsilon \rho i \beta \varepsilon \beta \lambda \eta \mu \varepsilon v \alpha c$ $242664911204720482846)$

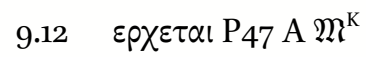
13.6 om. rell

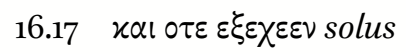
$\mathrm{C}^{\mathrm{a}} \quad \pi \varepsilon \rho ı \beta \varepsilon \beta \lambda \eta \mu \varepsilon v 0 \mathrm{l} P 1854205323292344235^{1} \mathfrak{M}^{\mathrm{A}}$ ( $\pi \varepsilon \rho і \beta \varepsilon \beta \lambda \eta \mu \varepsilon v 01 \mathrm{c} 1597$ 2059)

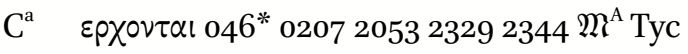
$\mathrm{C}^{\mathrm{a}} \quad$ sec. $x \alpha \mathrm{l} \mathrm{P} 046^{*} 0512053^{\text {txt }} \mathrm{m}^{\mathrm{A}}$ lat co Ir $^{\text {lat }}$ Bea
$18.7 \quad \alpha \cup \tau \eta \nu \mathrm{A} \mathrm{C} \mathfrak{M}^{\mathrm{K}}$

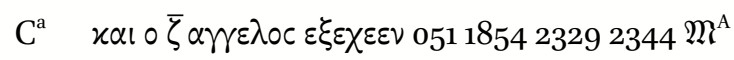 it $\mathrm{vg}^{\mathrm{cl}} \mathrm{sy}^{\mathrm{ph}}$ bo Prim Bea
$22.20 x \bar{\varepsilon} \bar{\imath} \tilde{v}$ rell

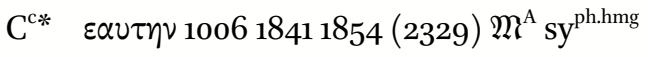
$\mathrm{C}^{\mathrm{a}} \quad \chi \bar{\varepsilon} \overline{\bar{\eta}} \overline{\cup \bar{\varepsilon}} 161^{\mathrm{s}} 20302050(2329) \mathrm{M}^{\mathrm{A}}$ gig sy ${ }^{\mathrm{ph}}$ co Prim Bea

At 4.1, $C^{a}$ substituted the masculine $\lambda \varepsilon \gamma \omega \nu$ for the more appropriate feminine $\lambda \varepsilon \gamma$ ouc $\alpha$. This shift more likely reflects $C^{a}$ s exemplar, although it could also betray his own grammatical concerns ${ }^{20}$ as the initial (and better attested) reading $\lambda \varepsilon \gamma \omega \nu \nu$ is syntactically incongruous. ${ }^{21}$

Similarly at 7.9, $C^{\text {a }}$ replaces $\pi \varepsilon p ı \beta \varepsilon \beta \lambda \eta \mu \varepsilon v o v c$ with $\pi \varepsilon \rho ı \beta \varepsilon \beta \lambda \eta \mu \varepsilon v o$, thus bringing the participle into syntactical congruence with the rest of the clause (cf. $\varepsilon \subset \tau \omega \tau \varepsilon c$ earlier in v. 9). ${ }^{22}$

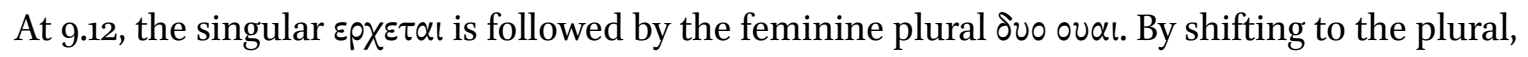
$\mathrm{C}^{\mathrm{a}}$ resolves the syntactical mismatch. While this correction could, again, reflect $\mathrm{C}^{\mathrm{a}}$ s concern for the correct Greek, the external support suggests that it probably stems from the corrector's exemplar. ${ }^{23}$

\footnotetext{
${ }^{19}$ Schmid, Studien, 2.45-49, 51.

${ }^{20}$ As will be seen below, a not insignificant number of $\mathrm{C}^{\mathrm{a}}$ corrections results in singular and weakly attested readings, suggesting that the corrector may occasionally have acted without consulting an exemplar. Where appropriate, then, alternative possibilities shall be noted throughout our analysis. Naturally, the weaker the attestation of a corrected reading, the stronger the case for its non-genetic origin.

${ }^{21}$ See Schmid, Studien, 2.236-237. On solecisms in Revelation (including 4.1), see BDF, § 136.

${ }^{22}$ On 7.9, see Schmid, Studien, $2.245^{-246 .}$

${ }^{23}$ Note esp. the early support of 0207 . Incidentally, Schmid, Studien, 2.172, does not cite this correction in his collation of 0207 .
} 
Of a different kind is the correction at 13.6. Considering that a Greek copulative clause typical-

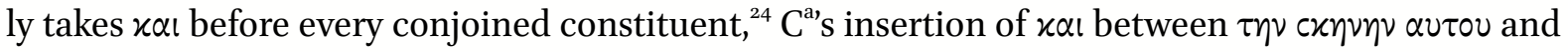

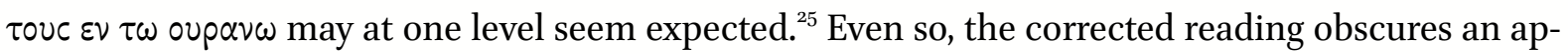
positive relationship between the two phrases. ${ }^{26}$

At 16.17, a scribal error went unnoticed during the scriptorium correction process. ${ }^{27} \mathrm{C}^{\mathrm{a}}$ altered

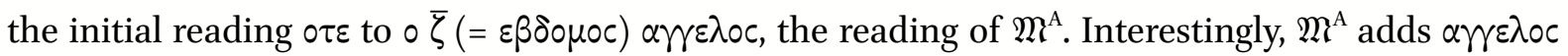
at each point of the present narrative $(16.3,4,8,10,12,17)$, save for the first instance (16.2). Whether $\mathrm{C}^{\mathrm{a}}$ s exemplar, too, read $\alpha \gamma \varepsilon \lambda \mathrm{\gamma}$ c consistently is a moot point, as the correction itself was probably not triggered by the absence of $\alpha \gamma \varepsilon \lambda \circ \mathrm{\gamma}$, but rather by the change in meaning occasioned by the initial replacement of an explicit subject - whether $0 \varepsilon \beta \delta \circ \mu \circ c \alpha \gamma \varepsilon \lambda \circ \circ$ or $\circ \varepsilon \beta \delta \circ \mu \circ c$ - with the temporal particle $\circ \tau \varepsilon$.

Schmid refers to the correction at 18.7 as $S^{a}$, but it does not come from the same class of $\mathrm{C}^{\mathrm{a}}$ corrections. Rather, it was made by the $\mathrm{C}^{\mathrm{C} *}\left(\mathrm{Schmid}\right.$ 's $\left.\mathrm{S}^{\mathrm{c}}\right)$ hand. ${ }^{28}$ The corrected reading is relatively widely attested and hence probably genetic, although an attentive reader could also have made it

\footnotetext{
${ }^{24}$ Cf. H.W. Smyth, Greek Grammar (rev. by Gordon M. Messing; Cambridge: Harvard University Press, 1956), § 2878.

${ }^{25}$ See B.M. Metzger, A Textual Commentary on the Greek New Testament (2nd ed.; London and New York: United Bible Societies, 1994), 674: "the presence of $x \alpha 1$... appears to be due to copyist who wished to alleviate the strained syntax."

${ }^{26}$ So D.E. Aune, Revelation 6-16 (Word Biblical Commentary 52b; Nashville: Thomas Nelson, 1998), 715, 745, who translates the phrase as "to blaspheme his name and his dwelling, that is, those who dwell in heaven" (emphasis added). In contrast, the meaning produced by the $\mathrm{C}^{\mathrm{a}}$ corrector is: "to blaspheme his name, his dwelling, and those who dwell in heaven."

${ }^{27}$ Cf. J. Hernández, Jr., Scribal Habits and Theological Influences in the Apocalypse: The Singular Readings of Sinaiticus, Alexandrinus, and Ephraemi (WUNT 2.218; Tübingen: Mohr Siebeck, 2006), 70, 72, 74, 84-85.

${ }^{28}$ As far as I am aware, Schmid, Studien, refers only to seven $S^{c}$ corrections at various points of his analysis: 2.2 (2.72), 2.4 (2.185), 11.1 (2.129, 240), 11.8 (2.129), 12.8 (2.129), 16.10 (2.129), 21.27 (2.70). Schmid's reference to 21.27, however, is incorrect, and he correctly cites it elsewhere as $S^{a}$. For further discussion of $C^{c *}\left(\right.$ and $\left.C^{c}\right)$ corrections, see Milne and Skeat, Scribes and Correctors, 49-50. Incidentally, $\mathrm{NA}^{28}$ cites the correction as $\aleph^{2}$, which seems misleading as the same siglum is used for $\mathrm{C}^{\mathrm{a}}$ corrections. The same applies to 11.4, 11.12, 14.8, 16.10, 16.18, and 19.13a, discussed below.
} 
without an exemplar. ${ }^{29}$ In any case, the correction comes from a different, most likely later and independent hand, and thus adds little to Schmid's cumulative argument concerning the relationship between $\mathrm{S}^{\mathrm{a}}$ corrections and Andreas.

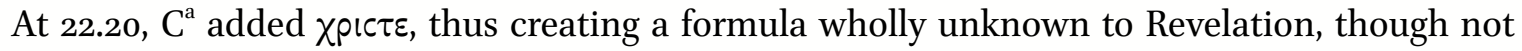
uncommon in the patristic literature. ${ }^{30}$ Considering the external attestation of the reading, it seems less likely that $C^{a}$ would have expanded the original address on his own initiative, even if such a possibility cannot be excluded with certainty. ${ }^{31}$

Two corrections appear in Schmid's collation of the Koine $\left(\mathfrak{M}^{\mathrm{K}}\right)$ text: ${ }^{32}$

\begin{tabular}{|c|c|c|c|}
\hline 11.9 & $\alpha \varphi 100 \mathrm{clv} p m$ & $\mathrm{C}^{\mathrm{a}}$ & $\begin{array}{l}\text { (1) } \alpha \varphi \text { n [c] ovclv } 0462053 \mathrm{M}^{\mathrm{K}} \text { gig vg } \mathrm{gl}^{\mathrm{l}} \text { bo | (2) } \\
\alpha \varphi \text { lovclv pm }\end{array}$ \\
\hline 20.8 & $\gamma \omega \gamma \kappa \alpha 1 \mu \alpha \gamma \omega \gamma^{33}$ solus & $\mathrm{C}^{\mathrm{a}}$ & 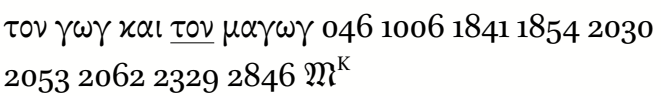 \\
\hline
\end{tabular}

As it is, Schmid's reference to 11.9 is misleading, as $\mathrm{C}^{\text {a }}$ never actually completed the correction.$^{34} \mathrm{It}$ seems that he initially began to alter the reading, but, having written the left vertical of $\eta$, abandoned the correction - for whatever reason. As $\mathrm{C}^{\mathrm{a}}$ s final judgment on (or a careless correction of)

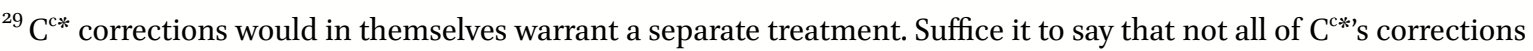
betray the use of an exemplar. See, e.g., 10.10, 11.3, 11.8, 12.6, 12.8b, 16.18, 18.9, 18.21, 19.7, where the corrected readings lack solid external support.

${ }^{30}$ Incidentally, of the 24 occurrences of xuploc incove $\chi p i c \tau o c$ in $\mathrm{NA}^{28}$, the formula never appears in the vocative. Apart from Acts 11.17, 28.31, and Jas 1.1, all the remaining occurrences are limited to the Pauline corpus: Rom 1.7, 13.14, 1 Cor 1.3, 6.11, 8.6, 2 Cor 1.2, 13.13, Gal 1.3, Eph 1.2, 6.23, Phil 1.2, 2.11, 3.20, 4.23, 1 Thess 1.1, 2 Thess 1.1, 1.12, 3.12, Phlm 3, 25.

${ }^{31}$ Expansion of christological titles is a common tendency in the transmission history. See further G. Zuntz, The Text of the Epistles: A Disquisition upon the Corpus Paulinum (The Schweich Lectures 1946; London: The British Academy, 1953), 182-184; P.M. Head, “A Text-Critical Study of Mark 1.1: 'The Beginning of the Gospel of Jesus Christ'” NTS 37 (1991), 627. See also B.M. Metzger and B.D. Ehrman, Text of the New Testament: Its Transmission, Corruption, and Restoration (4th ed.; New York and Oxford: Oxford University Press, 2005), 263-264.

${ }^{32}$ Schmid, Studien, $2.57,60$.

${ }^{33}$ CSP seems to be wrong in postulating a nonsensical reading $\tau \omega \gamma$. Admittedly, the letter is formed slightly differently than the following two gammas in that its horizontal bar lacks a finial. Apparently, though, Scribe A did not

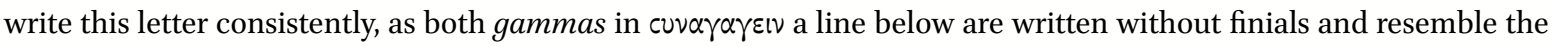
present instance.

${ }^{34}$ So also C. Tischendorf, ed., Novum Testamentum Sinaiticum sive Novum Testamentum cum epistula Barnabae et fragmentis Pastoris (Leipzig: F.A. Brockhaus, 1863), lxxv.
} 
the reading favours the original form, the corrected reading cannot be (contra Schmid) cited as agreeing with $\mathfrak{M}^{\mathrm{K}}$.

The initial reading at 20.8 is part of the larger omission, probably occasioned by the scribe's distraction at the line-ending. ${ }^{35}$ Thus, $\mathrm{C}^{\text {a }}$ probably at first noticed the omission of $\tau \eta c \gamma \eta c$ and, as he checked his exemplar, noticed the absence of $\tau$ ov not only before $\gamma \omega \gamma$, but also before $\mu \alpha \gamma \omega \gamma$, and effected the correction accordingly.

In discussing the relationship between the Andreas and the Koine text-forms, Schmid cites following corrections: ${ }^{36}$

\begin{tabular}{|c|c|c|c|}
\hline 1.18 & $\begin{array}{l}\text { om. A C P } 16111854205020532062 \\
2846 p c\end{array}$ & $\mathrm{C}^{\mathrm{a}}$ & $\alpha \mu \eta \nu 04610061841232923442351 \mathrm{M}$ sy \\
\hline $3 \cdot 5$ & $\begin{array}{l}\text { ov } \tau \omega \text { C A C } 10062329234423512846 \\
\text { al latt sy co }\end{array}$ & $\mathrm{C}^{\mathrm{a}}$ & 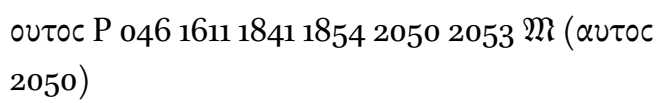 \\
\hline 19.6 & $\circ \theta \bar{c} \circ \underline{x \bar{c}} \eta \mu \omega \nu 178$ & $\mathrm{C}^{\mathrm{a}}$ & $\begin{array}{l}\chi_{\bar{c}}^{\bar{c}} \circ \overline{\theta \bar{c} \eta \mu \omega \nu} \mathrm{P} 04616111854203020532062 \\
23292344 \mathfrak{M} \text { lat sy } \mathrm{sa}^{\mathrm{ms}}\end{array}$ \\
\hline $20.9-10$ & om. solus & $\mathrm{C}^{\mathrm{a}}$ & 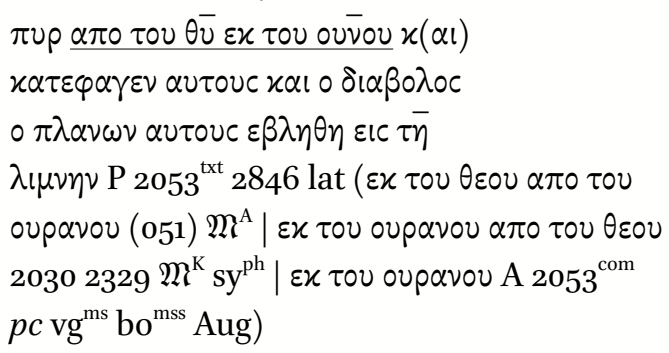 \\
\hline 21.20 & $\alpha u \varepsilon \theta v c \tau i v o c 20532062 p c$ & $\mathrm{C}^{\mathrm{a}}$ & $\alpha u \varepsilon \theta v c o c 10061841185420502344\left(2846^{c}\right) \mathfrak{M}$ \\
\hline
\end{tabular}

While the insertion of $\alpha \mu \eta \nu$ at 1.18 could be viewed as an arbitrary doxological addition, here it disrupts the flow of the sentence, and hence likely reflects the corrector's exemplar.

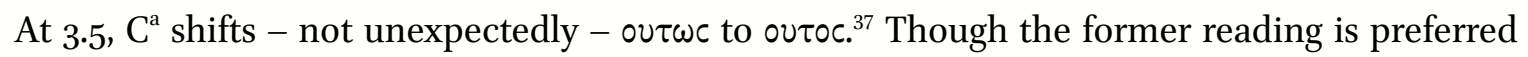

\footnotetext{
${ }^{35}$ See L. Havet, Manuel de critique verbale appliquée aux textes latins (Paris: Hachette, 1911), §§ 429-432; D.C. Greetham, Textual Scholarship: An Introduction (Garland Reference Library of the Humanities 1417; New York and London: Garland, 1994), 280; D. Jongkind, Scribal Habits of Codex Sinaiticus (TS 3.5; Piscataway: Gorgias Press, 2007), 245 .

${ }^{36}$ Schmid, Studien, $2.72-73,81-83$.

${ }^{37}$ Cf. J.K. Elliott, "A Short Textual Commentary on the Book of Revelation and the 'New' Nestle," NovT 56 (2014), 93.
} 
by Schmid (as well as by the editors of $\left.\mathrm{NA}^{28}\right),{ }^{38}$ the latter is read by the vast majority of the Greek tradition and significantly alters the meaning of the clause.

The initial reading at 19.6 is likely a scribal error. It is actually possible that $\mathrm{C}^{\text {a }}$ restored a reading that had also stood in the exemplar of Sinaiticus. If so, both Sinaiticus' and Cas exemplar support the majority reading, thus corroborating its external attestation further still.

At 20.9-10, $C^{a}$ corrects a lengthy singular omission, but even the corrected reading has rather meagre support. It seems possible, then, that the correction was not carried out accurately, so that the corrector's exemplar may have contained one of the majority readings.

The initial reading at 21.20 is supported by two important minuscules with the Oecumeniustype text. ${ }^{39}$ It is unfortunate that $\mathfrak{B}^{47}$ is not extant at this point, as it would be of great value in determining whether the reading of Sinaiticus is scribal or genetic in origin. In any event, the $\mathrm{C}^{\mathrm{a}}$ reading is, inter alia, attested by both $\mathfrak{M}^{\mathrm{A}}$ and $\mathfrak{M}^{\mathrm{K}}$.

Eight corrections are noted in Schmid's discussion of the A C Oecumenius text-form: ${ }^{40}$

\begin{tabular}{|c|c|c|c|}
\hline 1.19 & $\gamma \varepsilon v \varepsilon c \theta \alpha ı P^{98 v i d}$ C P $046205^{0}$ pm & $\mathrm{C}^{\mathrm{a}}$ & $\begin{array}{l}\gamma \varepsilon l \nu \varepsilon c \theta \alpha l(=\gamma l v \varepsilon c \theta \alpha l) A 1006161118411854 \\
20532062232923512846 \mathfrak{M}^{\mathrm{A}}\end{array}$ \\
\hline 6.4 & $\alpha u \tau \omega$ rell & $\mathrm{C}^{\mathrm{a}}$ & om. A $2344 p c$ \\
\hline $11.16 \mathrm{~b}$ & oเ $x \alpha \theta \eta \nu \tau \alpha \iota 046 \mathfrak{M}^{\mathrm{K}}$ & $\mathrm{C}^{\mathrm{a}}$ & $\begin{array}{l}\varkappa \alpha \theta \eta \nu \tau \alpha \iota P^{47} \text { C } 100616111841205323442846 \\
p c\left(\varkappa \alpha \theta \eta \mu \varepsilon \nu \text { เ A P } 05118542329(2351) \mathfrak{M}^{A}\right)\end{array}$ \\
\hline 14.8 & om. $\mathfrak{P}^{47} 100618411854(2846) p c \mathrm{sy}^{\mathrm{ph}}$ & $\mathrm{C}^{\mathrm{c} *}$ & 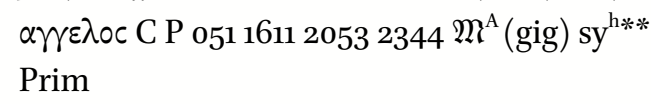 \\
\hline $\begin{array}{l}14.8- \\
9 a^{41}\end{array}$ & om. $32551745^{6}$ & $\mathrm{C}^{\mathrm{a}}$ & 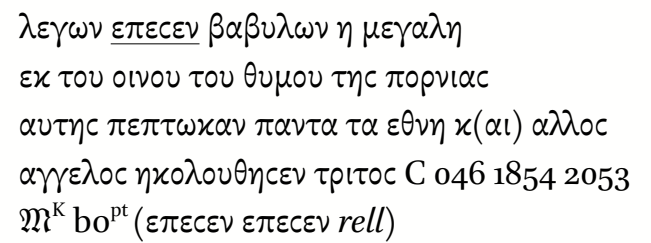 \\
\hline
\end{tabular}

\footnotetext{
${ }^{38}$ Incidentally, Schmid, Studien, 2.73, settles the matter based on the witness of the versions, which otherwise don't figure prominently in his discussions.

${ }^{39}$ See further Schmid, Studien, 2.24-25.

${ }^{40}$ Schmid, Studien, 2.91, 94-95, 98-99, 102, 104-105.

${ }^{41}$ Schmid treats $14.8-9$ as three distinct readings (cited here as $14.8-9 \mathrm{a}, \mathrm{b}, \mathrm{c}$ ), though it is actually only one correction. In discussing Schmid's citations, I have retained this (somewhat artificial) distinction, but I list it as a single
} 
14.8-9b om. 325517456

21.6

21.18
$\mathrm{C}^{\mathrm{a}} \quad \lambda \varepsilon \gamma \omega \nu \varepsilon \pi \varepsilon c \varepsilon \nu \beta \alpha \beta \nu \lambda \omega \nu \eta \mu \varepsilon \gamma \alpha \lambda \eta$

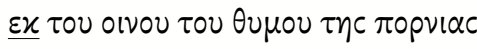

$\alpha \nu \tau \eta c \pi \varepsilon \pi \tau \omega x \alpha \nu \pi \alpha \nu \tau \alpha \tau \alpha \varepsilon \theta \nu \eta x(\alpha \mathrm{l}) \alpha \lambda \lambda \circ c$

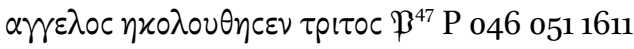
185423292344 M gig Spec Prim( $\eta$ post $\mu \varepsilon \gamma \alpha \lambda \eta$ A C 1006184120532846 al lat sy)

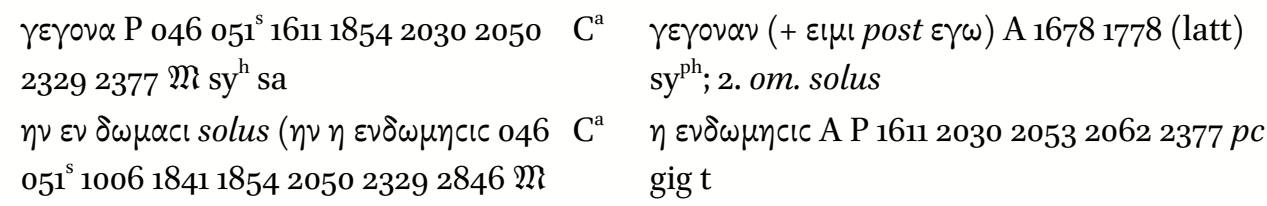

At 1.19, both the initial and the corrected reading have significant external support support. One could possibly argue that this could be just an arbitrary grammatical improvement, because, in the New Testament, $\mu \varepsilon \dot{\lambda} \lambda \varepsilon \imath \nu$ is usually followed by the present infinitive. ${ }^{42}$ Nevertheless, since Revelation exhibits much greater fluctuation in this respect, ${ }^{43}$ the genetic origin seems more plausible.

The initial, somewhat pleonastic, reading at 6.4 is supported by the vast majority of witnesses. The correction smooths the clause out by deleting the superfluous $\alpha v \tau \omega$. Notwithstanding the support of A 2344, one cannot exclude a possibility that such a correction may have occurred independently.

At 11.16b, the initial reading is well-attested. Unlike most other witnesses, however, Sinaiticus (followed by $10061841 \mathrm{al}$ ) also inserts $\varkappa \alpha \iota$ before $\varepsilon \pi \varepsilon c \alpha \nu$, making the relative construction even more awkward. By expunging ol, $\mathrm{C}^{\mathrm{a}}$ attempted to ameliorate the construction - whether based on the exemplar or not.

The initial reading at 14.8 is also shared by $\mathfrak{P}^{47}$, Sinaiticus' closest ally, and is unlikely a scribal error. By inserting $\alpha \gamma \varepsilon \lambda \lambda_{0 c}, C^{\mathrm{c*}}$ alters it to a more widely attested reading, preferred by Schmid as

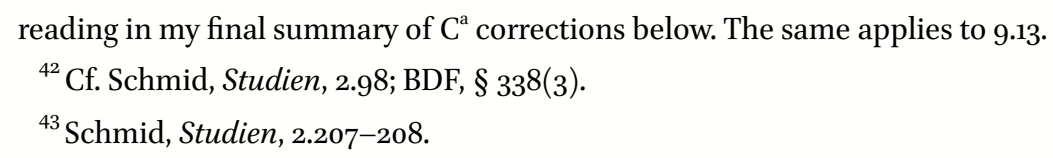


well as the editors of $\mathrm{NA}^{28}{ }^{44}$ The correction could be either due to the corrector's exemplar or due to the influence of the context (cf. 14.6,9).

As noted, at 14.8-9a $\mathrm{C}^{\mathrm{a}}$ restores a lengthy scribal omission. The present variation-unit concerns omission of the second $\varepsilon \pi \varepsilon \subset \varepsilon \nu$ within the correction. Since the external evidence for the omission is by no means meagre, we probably have a genetic agreement, although the possibility of accidental haplography cannot be excluded.

The variation-unit at $14.8-9 \mathrm{~b}$ concerns addition/omission of the relative pronoun $\eta$ (misleadingly accented as $\hat{\eta}$ in Schmid's discussion ${ }^{45}$ ). The reading is widely attested.

The initial reading at 21.6 is attested in both later text-forms and reflects a misunderstanding of the syntax..$^{46}$ The correction itself is puzzling: $C^{a}$ initially altered $\gamma \varepsilon \gamma o v \alpha$ to $\gamma \varepsilon \gamma$ ov $\alpha$. Because $C^{a}$ did not supply $\varepsilon ı \iota$ in the following part of the verse, however, the result is a singular conflation of the majority reading with that of A 1678 1778. Oddly, rerovav was subsequently cancelled. Perhaps the corrector's Vorlage was furnished with a correction or a reader's note that confused him somehow. Alternatively, the corrector may have - initially or later - departed from his Vorlage. All the same, the problematical nature of this correction precludes any further judgement on the precise wording of the corrector's exemplar at this point.

The reading $\eta \nu \varepsilon \nu \delta \omega \mu \alpha c$ at 21.18 seems to be a scribal misreading of $\eta \nu \eta \varepsilon v \delta \omega \mu \eta c \iota c$, a secondary variant shared by most witnesses. The correction exhibits a genuine textual shift toward the superior reading $\eta \varepsilon v \delta \omega \mu \eta c\left\llcorner.^{47}\right.$

\footnotetext{
${ }^{44}$ See Schmid, Studien, 2.104-105.

${ }^{45}$ Schmid, Studien, 2.91.

${ }^{46}$ So Schmid, Studien, 2.94 .

${ }^{47}$ So Schmid, Studien, 2.95 .
} 
Three corrections appear in Schmid's collation of the $\mathfrak{B}^{47} \aleph$ Origen text-form: ${ }^{48}$

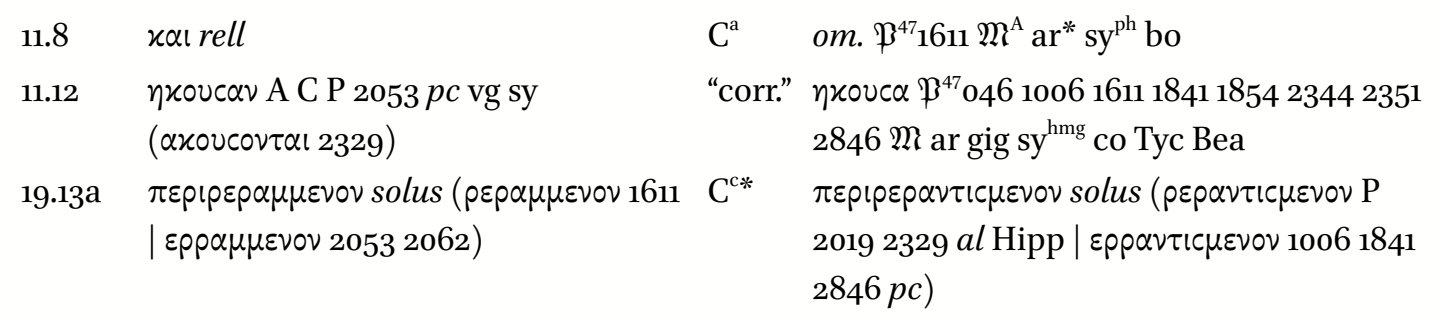

The $x a$ read initially at 11.8 is well-attested and overall a superior reading. On the other hand, $\mathrm{C}^{\mathrm{a}}$ cancelled it, thus bringing the reading into conformity with $\mathfrak{P}^{47}$ and the Andreas tradition. Taking into account $C^{\mathrm{a}}$ s addition of $\alpha v \tau \omega \nu$ after the following $x \bar{c}$, the entire corrected reading aligns neatly with $\mathfrak{M}^{\mathrm{A}}$ at this point.

Schmid's reference to $\mathrm{S}^{\mathrm{a}}$ at 11.12 seems overconfidence: the correction is comprised of an erasure which cannot be attributed to a specific corrector with any confidence. ${ }^{49}$ Since the corrected reading is, inter alia, supported by $\mathfrak{P}^{47}$, the erasure could be due to the original hand, who had initially used the plural under the influence of the surrounding context. ${ }^{5^{\circ}}$ As the correction cannot be assigned with certainty, however, its value is, for Schmid's purposes, rather limited.

At 19.13a, the singular initial reading $\pi \varepsilon p ı \varepsilon p \alpha \mu \mu \varepsilon \varepsilon v 0 v$ is most likely due to the scribe.${ }^{51} \mathrm{C}^{\mathrm{c*}}$ 's (also

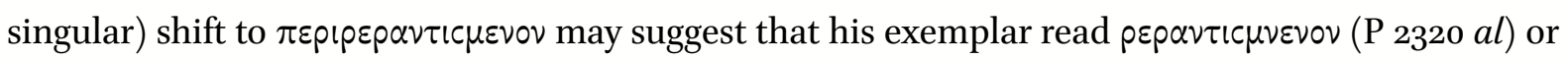

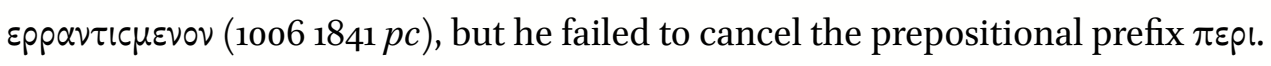

In examining the relationship between Sinaiticus and $\mathfrak{M}^{\mathrm{K}}$, Schmid cites one $\mathrm{S}^{\mathrm{a}}$ correction: $:^{5^{2}}$

\footnotetext{
${ }^{48}$ Schmid, Studien, 2.114 n. 4, 115-116. Schmid (125) also cites 11.8 as an "Analog" to 20.10.

${ }^{49} \mathrm{Cf}$. Tischendorf, Novum Testamentum Sinaiticum, lxxv, who only notes: "v erasum." In the same vein, Hoskier, Concerning the Text of the Apocalypse, 2.298 , cites the correction as " $\aleph$ avel c."

${ }^{50}$ Although it is difficult to determine on the basis of the digital image alone, it seems that, before the erasure, the deletion may have been marked by an obelus, as there are traces of a diagonal stroke written across the original diagonal of the $n u$. This kind of deletion is typical of scriptorium corrections. Cf. Malik, "Corrections," 243-244 n. 134.

${ }^{51}$ Cf. Elliott, “A Textual Commentary," 98.

${ }^{52}$ Schmid, Studien, 2.134 .
} 


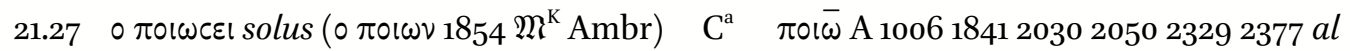

$$
\begin{aligned}
& \text { ( } \pi 0 \text { เovv P } 046051^{\mathrm{s}} 1611^{\mathrm{s}} 20532062 \mathfrak{M}^{\mathrm{A}} \text { gig Apr) }
\end{aligned}
$$

At 21.27, $\mathrm{C}^{\mathrm{a}}$ rectifies the nonsensical reading $\pi$ oเ $\omega \varepsilon_{\varepsilon l}$ and cancels the article, thereby shifting the reading to that of Alexandrinus and others. Although the initial reading is a scribal error "whose occurrence def[ies] easy explanation," ${ }^{53}$ it seems clear that his Vorlage included an article. The corrected reading is most likely genetic.

In his treatment of the problematical variation-unit at 18.3 , Schmid remarks on the parallel at 14.8 that also involves one $S^{\text {a }}$ correction: $:^{54}$

$$
\text { 14.8-9c om. } 32551745^{6}
$$

$$
\begin{aligned}
& \mathrm{C}^{\mathrm{a}} \quad \lambda \varepsilon \gamma \omega \nu \varepsilon \pi \varepsilon \subset \varepsilon \nu \beta \alpha \beta \nu \lambda \omega \nu \eta \mu \varepsilon \gamma \alpha \lambda \eta
\end{aligned}
$$

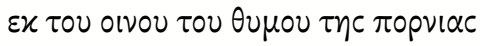

$$
\begin{aligned}
& \alpha \nu \tau \eta c \pi \varepsilon \pi \tau \omega x \alpha \nu \pi \alpha \nu \tau \alpha \tau \alpha \varepsilon \theta \nu \eta x(\alpha \mathrm{l}) \alpha \lambda \lambda \circ c
\end{aligned}
$$

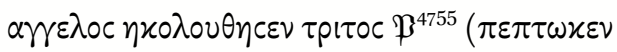

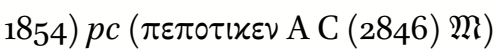

Schmid's discussion concerns variation of $\pi \varepsilon \pi 0 \tau \iota \kappa \varepsilon v / \pi \varepsilon \pi \tau \omega \kappa \alpha \nu$, initially absent from Sinaiticus.

The $\mathrm{C}^{\mathrm{a}}$ correction reads $\pi \varepsilon \pi \tau \omega \varkappa \alpha \nu$, a secondary reading that probably owes its origin to the influence of the preceding $\varepsilon \pi \varepsilon \subset \varepsilon \nu \beta \alpha \beta \nu \lambda \omega \nu .{ }^{6}{ }^{6}$ The reading's slim support might be non-genetic, as harmonisation to the immediate context was a pervasive tendency across the tradition, ${ }^{57}$ and morphologically similar words such as $\pi \varepsilon \pi \circ \tau i x \varepsilon \nu / \pi \varepsilon \pi \tau \omega \varkappa \alpha \nu$ lend themselves well to such a visual

\footnotetext{
${ }^{53}$ Hernández, Scribal Habits, 65.

${ }^{54}$ Schmid, Studien, 2.142-143.

${ }^{55}$ F. G. Kenyon, ed., The Chester Beatty Biblical Papyri, 3: Pauline Epistles and Revelation, Text (London: Emery Walker, 1934), 29, edits: $\pi \varepsilon \pi \tau \omega[\varkappa \varepsilon] \nu$. Schmid's ( Studien, 2.142) citation of $\mathfrak{P}^{47}$ as $\pi \varepsilon \pi \tau \omega[..] \nu$ seems unnecessarily conservative. Note that, later on, Schmid remarks that " $S$ a und $P^{47}$ ebenfalls $\pi \varepsilon \pi \tau \omega \varkappa \alpha \nu$ (oder evtl. $\pi \varepsilon \pi \tau \omega \varkappa \varepsilon \nu$ ) lesen."

${ }^{5}$ So Schmid, Studien, 2.143 .

${ }^{57}$ See, e.g., E.C. Colwell, "Method in Evaluating Scribal Habits: A Study of P45, P66, P75," in Studies in Methodology in Textual Criticism of the New Testament, ed. E. C. Colwell (Leiden: Brill, 1969), 113-114; J.R. Royse, Scribal Habits in Early Greek New Testament Papyri (NTTSD 36; Leiden and Boston: Brill, 2008), 735, 737-738; P.M. Head, "Observations on Early Papyri of the Synoptic Gospels, especially on the "Scribal Habits", Bib 71 (1990), 246; P.M. Head, "The Habits of New Testament Copyists: Singular Readings in the Early Fragmentary Papyri of John," Bib 85 (2004), 407-408; Jongkind, Scribal Habits, 247, 254; Hernández, Scribal Habits, 193.
} 
confusion.

\subsection{Patristic Citations}

Three variation-units discussed under Origen's text involve corrections: $:^{8}$

$$
\begin{aligned}
& 11.8 \text { xal rell } \quad \mathrm{C}^{\mathrm{a}} \quad \text { om. } \mathfrak{P}^{47} 1611 \mathrm{M}^{\mathrm{A}} \text { ar* } \mathrm{sy}^{\mathrm{ph}} \text { bo } \\
& \text { 14.3 alrell } \quad \mathrm{C}^{\mathrm{a}} \quad \text { om. } 79220532846 \mathrm{al} \\
& \text { 19.13b } \quad \text { } \varepsilon x \lambda \eta \tau \text { (vel } x \varepsilon x \lambda \eta \tau 0) \text { solus } \quad C^{\mathrm{a}} \quad \text { } \quad \text { } \varepsilon x \lambda \eta \tau \alpha \mathrm{l} \text { A P } 04610061611184118542030
\end{aligned}
$$

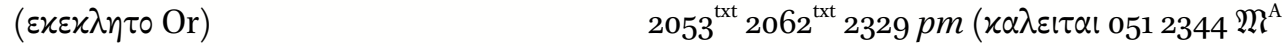

$$
\begin{aligned}
& \left.\operatorname{Ir}^{\text {lat }}\right)
\end{aligned}
$$

Although the corrected reading at 11.8 is, as noted, genetic, it adds little to Schmid's discussion of Origen's text, as Origen's citation is rather free and hence "ohne Beweiskraft." ${ }^{59}$

At 14.3, Sinaiticus has a well-attested anaphoric article before $\varepsilon \varkappa \alpha \tau o v$. Surprisingly, $C^{\text {a }}$ deleted the article, altering the reading to that with very sparse attestation. It seems impossible definitively to account for this intervention: while we could invoke the corrector's exemplar, such an explanation is rendered problematic by the reading's meagre support. Other conceivable explanations such as harmonisation to Rev $14.1^{60}$ or incongruity of grammatical genders (the following participle is in the masculine) do not seem to be particularly impressive either. In any event, the $C^{a}$ reading is most likely non-genetic.

The initial reading at $19.13 \mathrm{~b}$ is probably a conflation of $\chi \varepsilon x \lambda \eta \tau \alpha \iota$ and the following article $\tau 0$, resulting, effectively, in a pluperfect form $\varkappa \varepsilon \varkappa \lambda \eta \tau 0 .{ }^{61}$ Probably, $\mathrm{C}^{\mathrm{a}}$ simply restores the intended reading of Sinaiticus.

\footnotetext{
${ }^{58}$ Schmid, Studien, 2.154-155, and also 128 n. 2.

${ }^{59}$ Schmid, Studien, 2.154 .

${ }^{60}$ Incidentally, the numeral in Origen's citation of 14.1 (Comm. Jo. 1.2), too, has an article - apparently without external support.

${ }^{61}$ Hence, Hernández, Scribal Habits, 83 , classifies the reading as a change in tense. Alternatively, the Vorlage of Sinaiticus may have agreed with Origen (Comm. Jo. 2.5) in reading a pluperfect form $\varepsilon \varkappa \varepsilon \chi \lambda \eta \tau o$. If so, the scribe would have had to drop the augment and omit the article $\tau$ o by haplography. Less likely still is CSP's transcription $x \varepsilon \chi \lambda \eta \tau$.
} 
Three $S^{a}$ readings appear in Schmid's discussion of Hippolytus of Rome: ${ }^{62}$

\begin{tabular}{|c|c|c|c|}
\hline 11.3 & $\pi \varepsilon \rho 1 \beta \varepsilon \beta \lambda \eta \mu \varepsilon v o v c$ A P 0462329 al & $\mathrm{C}^{\mathrm{a}}$ & $\begin{array}{l}\pi \varepsilon \rho ı \beta \varepsilon \beta \lambda \eta \mu \varepsilon v \text { o rell }(\pi \varepsilon \rho \curlywedge \beta \varepsilon \beta \lambda \eta \mu \varepsilon v \text { เс } 8082039 \\
20712075207620772258)\end{array}$ \\
\hline 11.4 & $\varepsilon \subset \tau \omega \tau \varepsilon c$ rell & $\mathrm{C}^{\mathrm{*} *}$ & $\varepsilon c \tau \omega c \alpha \mathrm{P} P 10061841185420532846 \mathfrak{M}^{\mathrm{A}}$ \\
\hline 8.8 & xpivac rell & $\mathrm{C}^{\mathrm{a}}$ & xpivwv $1250424616204821862428 \mathrm{al}$ \\
\hline
\end{tabular}

The initial reading at 11.3, though relatively well-attested, is "offenkundig sinnlos." ${ }^{{ }^{63}}$ The corrected nominative reading is strongly supported and thus likely genetic.

The well-attested masculine participle at 11.4 is syntactically incongruent, as it belongs to a construction governed by the feminine article. It is interesting that the reading was corrected by the later $\mathrm{C}^{\mathrm{c*}}$ rather than $\mathrm{C}^{\mathrm{a}}$, whose (surely different) exemplar has been said to be related to the Andreas text.

At 18.8, the initial reading is widely attested. Surprisingly, $\mathrm{C}^{\mathrm{a}}$ altered it to a reading with extremely weak attestation - a reading, incidentally, of the Textus Receptus. Importantly for Schmid's purposes, the correction (with which the text of Hippolytus disagrees) most likely does not betray a genuine genetic relationship.

\subsection{Early Fragments}

In discussing early fragmentary manuscripts of Revelation, Schmid refers to two corrections. The first one appears in his collation of $0169:^{64}$

$$
\begin{aligned}
& \text { 4.2 } \quad \varepsilon \cup \theta \varepsilon \omega c \text { rell }
\end{aligned}
$$

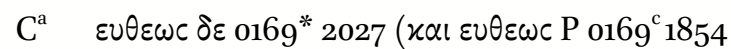

$$
\begin{aligned}
& 23442846 \mathfrak{M}^{\mathrm{A}} \mathrm{vg}^{\mathrm{cl}} \mathrm{sy} \text { ) }
\end{aligned}
$$

At 4.2, 0169 * lacks $x \alpha \iota$ before $\varepsilon v \theta \varepsilon \omega c$. Schmid's collation indicates that the corrected text of 0169 in-

\footnotetext{
${ }^{62}$ Schmid, Studien, 2.157, 161, 165 .

${ }^{63}$ See further Schmid, Studien, 2.101.

${ }^{64}$ Schmid, Studien, 2.172.
} 
cludes $x \alpha$ l, thus agreeing with the corrected reading of Sinaiticus, as well as $\mathfrak{M}^{\mathrm{A}}$. However, the correction clearly reads $\varepsilon \cup \theta \varepsilon \omega c \delta \varepsilon$, hence Schmid's postulated agreement with $0169^{c}-$ and, more importantly, with Andreas - is illusory. Moreover, it is uncertain whether the Vorlage of o169 contained a shorter text, as the correction might have been made by the original scribe, using the same exemplar. Since the omission took place at a line break, it could easily have been accidental. As for the correction, the sole support of $0169^{*} 2027$ most likely suggests a non-genetic origin, perhaps reflecting $\mathrm{C}^{\mathrm{a}} \mathrm{s}$ avoidance of asyndeton.

Another $S^{a}$ correction is noted in Schmid's collation of $0207:^{65}$

$$
\begin{aligned}
& \text { 9.13b } \quad \varphi \omega \nu \bar{n} \text { solus } \quad \mathrm{C}^{\mathrm{a}} \quad \varphi \omega \nu \eta c \mu l \alpha c \varepsilon \varkappa \tau \omega \nu \varkappa \varepsilon p \alpha \tau \omega \nu P^{47} \mathrm{~A} 02071611 \\
& 20532344 p c \text { lat sy }{ }^{\mathrm{h}} \text { co }
\end{aligned}
$$

Here the scribe initially omitted the entire phrase $\mu \ltimes \nu \varepsilon \varkappa \tau \omega \nu[\tau \varepsilon c c \alpha \rho \omega \nu] \chi \varepsilon \rho \alpha \tau \omega \nu$. Schmid cites this correction in agreement with the omission of $\tau \varepsilon c c \alpha \rho \omega \nu$ in 0207 . Though omission by homoioteleuton cannot be entirely excluded, the reading is more likely genetic.

\subsection{The Use of Language}

Schmid cites three corrections in discussing morphological issues: ${ }^{66}$
$2.20 \quad \alpha \varphi \varepsilon ı$ rell
$\mathrm{C}^{\mathrm{a}} \quad \alpha \varphi \eta x \alpha c 16112050 \mathrm{pc} \mathrm{vg}^{\mathrm{ms}}$ sy co

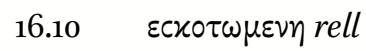
$C^{c *} \quad \varepsilon c x o \tau i c \mu \varepsilon v \eta 0461611 p c$
$20.12 \quad$ om. 12186
$\mathrm{C}^{\mathrm{a}} \quad x(\alpha \mathrm{l}) \alpha \lambda \lambda_{0} \beta \mathrm{s} \beta \lambda_{10 \nu} \eta \nu \varepsilon \omega x \theta \eta \mathrm{m}$

The form $\alpha \varphi \varepsilon ı$ at 2.20 is attested by the vast majority of the tradition. Conversely, the reading introduced by $\mathrm{C}^{\mathrm{a}}$ is found in only a handful of late manuscripts. This scant support, then, may possibly be non-genetic, so that $\mathrm{C}^{\mathrm{a}}$ made the correction on his own accord - perhaps under the influ-

\footnotetext{
${ }^{65}$ Schmid, Studien, 2.172.

${ }^{66}$ Schmid, Studien, $2.180,182-183$, and also 128 n. 2.
} 
ence of $\varepsilon \delta \omega x \alpha$ in v. 21 - although the aorist is, admittedly, not well-suited for the present context. ${ }^{67}$

At 16.10, we have a well-attested initial reading, which $C^{\text {c** }}$ altered to a reading whose support is overall scant and much later. While is is possible that $\mathrm{C}^{\text {(*)' }}$ exemplar contained a reading attested by 046 and a few minuscules, it seems just as likely that he altered the form based on his personal preference.

At 20.12, the scribe probably made an omission at a line break (after $\beta \iota \beta \lambda \iota \alpha \eta v \varepsilon \omega \chi \vartheta \eta)$. Schmid cites the correction as an example of the double augment in $\eta v \varepsilon \omega \chi \vartheta \eta$, which is, in fact, read by most witnesses in $\mathfrak{M}^{\mathrm{K}}$ and $\mathfrak{M}^{\mathrm{A}}$. The widespread attestation of this orthography may thus suggest a genetic origin, though it could also be a harmonisation to the preceding $\eta v \varepsilon \omega \chi \vartheta \eta$, found in the original text of Sinaiticus.

Two corrections appear in Schmid's discussion of the use of article: ${ }^{68}$

\begin{tabular}{|c|c|c|c|}
\hline $11.16 \mathrm{a}$ & $\varepsilon \iota x о c l ~ \tau \varepsilon c c \alpha p \varepsilon c$ A $2053^{\mathrm{txt}} p c$ & $\mathrm{C}^{\mathrm{a}}$ & 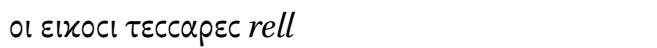 \\
\hline 21.27 & 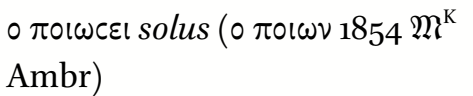 & $\mathrm{C}^{\mathrm{a}}$ & $\begin{array}{l}\pi \circ เ \bar{\omega} \text { A } 100618412030205023292377 \text { al } \\
\left(\pi \circ \text { เovv P } 0460^{\mathrm{s}}{ }^{\mathrm{s}} 161^{\mathrm{s}} 20532062 \mathrm{M}^{\mathrm{A}} \text { gig Apr) }\right.\end{array}$ \\
\hline
\end{tabular}

Though the omission at 11.16a is not singular, it might still be a scribal error, as omission of small words occurs frequently in Sinaiticus. ${ }^{69}$ Moreover, the article does not carry much of its anaphoric force, as the previous mention of the twenty-four elders (5.8) is rather removed from the present context. Importantly, Schmid's reference to the omission of or by $S^{a}$ is thus incorrect. ${ }^{70}$

As discussed, the initial reading at 21.27 is nonsensical, though the Vorlage of Sinaiticus most likely contained an article. By deleting the article, $C^{a}$ shifts the reading to that of Alexandrinus (in-

\footnotetext{
${ }^{67}$ It seems that the original present $\alpha \varphi \varepsilon ı$ fits better with the preceding $\varepsilon \chi \omega \varkappa \alpha \tau \alpha$ cov: Jesus' rebuke comes precisely at the time when the church was still tolerating Jezebel.

${ }^{68}$ Schmid, Studien, 2.196, 199.

${ }^{69}$ Cf. Jongkind, Scribal Habits, 244.

${ }^{70}$ Note that Schmid elsewhere cites $S^{*}\left(=\aleph^{*}\right)$ in support of the omission at 11.16. Cf. Schmid, Studien, 2.135.
} 
ter alia).

In discussing the use of grammatical cases, Schmid cites one correction: ${ }^{71}$

$$
\begin{aligned}
& \text { 9.13a } \varphi \omega \nu \bar{\eta} p m \quad C^{\mathrm{a}} \quad \varphi \omega \nu \eta c \mu l \alpha c \varepsilon \varkappa \tau \omega \nu \varkappa \varepsilon \rho \alpha \tau \omega \nu 469^{*} 7432026205^{1} \\
& 2055206420672329
\end{aligned}
$$

Since the shift to the genitive at 9.13a occurs within $\mathrm{C}^{\mathrm{a}}$ s larger correction, it could be genetic, although the corrector's preference for the genitive after $\alpha$ xovहlv is perhaps a more likely possibility, especially in view of the reading's sparse attestation.

Schmid's discussion of pronouns involves an $\mathrm{S}^{\mathrm{a}}$ correction at $18.7:^{7^{2}}$

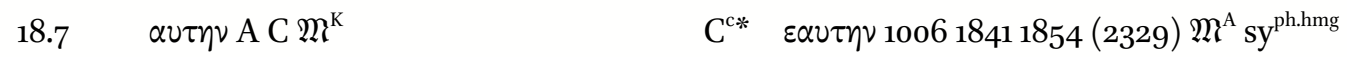

Schmid's case for the reading $\alpha v \tau \eta \nu$ seems corroborated still further, since the correction, despite its weighty attestation, need not have been genetic, as only a minor orthographical matter is involved. Besides, the correction is in any case quite late.

Schmid's discussion of the use of prepositions involves the following correction: ${ }^{73}$

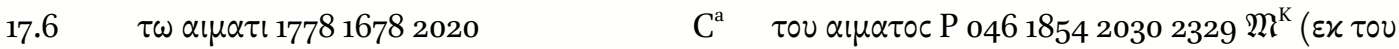

$$
\begin{aligned}
& \alpha(\mu \alpha \tau \circ \mathrm{pm})
\end{aligned}
$$

At $17.6, C^{a}$ shifts the sub-singular dative to the better attested genitive. The initial reading may have been phonetically conditioned, ${ }^{74}$ so that the scribe merely deviated from the reading of his exemplar. In any event, Schmid cites the correction amongst witnesses to the (probably secondary) omission of $\varepsilon \varkappa$. Whether $\mathrm{C}^{\mathrm{a}}$ s exemplar had $\varepsilon \varkappa$ or not is a moot point, as his intervention was limited to the shift of the grammatical case.

\footnotetext{
${ }^{71}$ Schmid, Studien, 2.200.

${ }^{72}$ Schmid, Studien, 2.206.

${ }^{73}$ Schmid, Studien, 2.214.

${ }^{74}$ On interchange of ov and $\omega(\mathrm{l})$, see F.T. Gignac, A Grammar of the Greek Papyri of the Roman and Byzantine Periods, vol. 1: Phonology, vol. 2: Morphology (Testi e documenti per lo studio dell'antichità 55; Milano: Istituto Editoriale Cisalpino-La Goliardica, 1976-1981), 1.208-209.
} 
Two corrections cited by Schmid involve stereotypical expressions: ${ }^{75}$

\begin{tabular}{|c|c|}
\hline. & 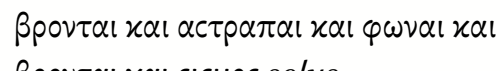 \\
\hline & 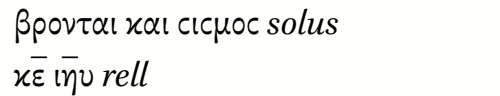 \\
\hline
\end{tabular}

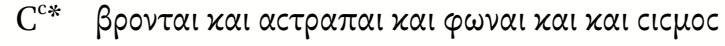
solus (om. sec. xal 920185920272256 )

$\mathrm{C}^{\mathrm{a}} \quad \chi_{\bar{\varepsilon}} \bar{\imath} \cup \chi_{\bar{\varepsilon}} 1611^{\mathrm{s}} 20302050(2329) \mathrm{M}^{\mathrm{A}}$ gig sy ${ }^{\mathrm{ph}}$ co Prim Bea

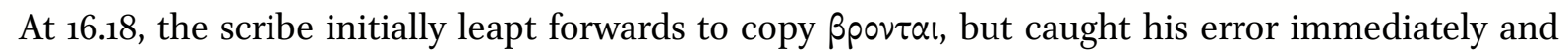
copied the phrase in a different sequence.$^{76}$ In making this ad hoc correction, however, he failed to

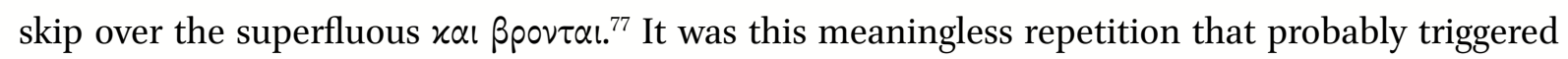
the $C^{\mathrm{c*}}$ correction whose execution, however, seems equally incompetent, as it only cancels

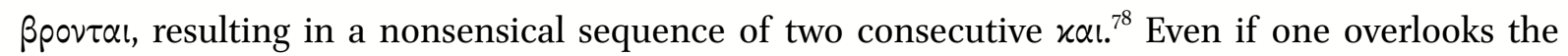
repetition of $x \alpha$, the resultant reading lacks firm genetic support.

The addition at 22.20 also appears on Schmid's list of inauthentic occurrences of the "Doppelname" incovc $\chi$ pictoc. $^{79}$ Whether deriving from the exemplar or not - and the former seems somewhat more likely ${ }^{80}$ - the correction appears to be the earliest evidence in support of the longer reading.

One correction is cited in Schmid's discussion of the constructio ad sensum: ${ }^{81}$

$$
\text { 4.5-6 om. } 4566286802065
$$

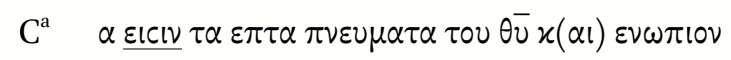

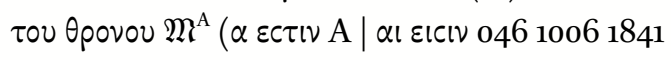
$\mathfrak{M}^{\mathrm{K}}$ )

The sub-singular omission at $4 \cdot 5^{-6}$ is most likely due to scribal leap. $\mathrm{C}^{\text {a’s }}$ correction involves a plur-

\footnotetext{
${ }^{75}$ Schmid, Studien, 2.226-228.

${ }^{76}$ On this type of scribal behaviour, see Royse, Scribal Habits, 157; Colwell, "Scribal Habits," 116; Hernández, Scribal Habits, 75 .

${ }^{77}$ Thus, the Vorlage of Sinaiticus most likely accorded with A 016310061611184118542053 2062, and not its usual ally $\mathfrak{P}^{47}$ which is here followed by $0512329 \mathrm{~m}^{\mathrm{K}}$.

${ }^{78}$ So Tischendorf, Novum Testamentum Sinaiticum, lxxv: "C ${ }^{\mathrm{c}}$ improbavit (licet $x \alpha$ intactum reliquerit)."

${ }^{79}$ Cf. Schmid, Studien, 2.226 .

${ }^{80}$ See our previous discussion on p. 8 above.

${ }^{81}$ Schmid, Studien, 2.231 n.3.
} 
al constructio ad sensum, agreeing - against Alexandrinus ${ }^{82}-$ with $\mathfrak{M}^{\mathrm{A}}$. Schmid apparently prefers the $\mathrm{C}^{\mathrm{a}}$ reading, since he notes it amongst those instances where the original plural was subsequently altered to the singular.

Among several variation-units involving language irregularities discussed by Schmid, the one at 9.12 involves an $S^{a}$ correction:
9.12
$\varepsilon p \chi \varepsilon \tau \alpha l \mathrm{P} 47 \mathrm{~A} \mathfrak{M}^{\mathrm{K}}$

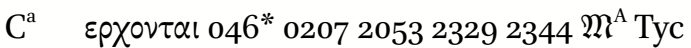

As discussed, this correction rectifies an obvious incongruence, which, however, is most likely part of the earliest attainable text. ${ }^{8}$ While it is uncertain whether the correction reflects $\mathrm{C}^{\text {as }}$ s exemplar or his own grammatical concerns, the corrected reading appears to predate all other known witnesses to this variant.

\section{Synthesis and Concluding Reflections}

Throughout our discussion we observed that, as Hernández recently argued, none of Schmid's $S^{a}$ corrections originated in the scriptorium, and thus cannot be dated to the fourth century. Moreover, even Schmid's monolithic S label seems misleading, as not all the corrections so designated were made by the same hand. If we follow CSP's assignment, thirty-five of these corrections were made by $\mathrm{C}^{\mathrm{a}}$, six by $\mathrm{C}^{\mathrm{c} *},{ }^{84}$ and one correction seems impossible to assign. It follows, then, that textual affinities of these corrections cannot be studied together as if they constituted one class of readings, as in both cases the correctors must have used different Vorlagen. Furthermore, there is a good chance that the correctors occasionally altered readings based on their preference rather

\footnotetext{
${ }^{82}$ Cf. Hernández, Scribal Habits, 121.

${ }^{83}$ So Schmid, Studien, 2.246.

${ }^{84}$ Cf. Tischendorf, Novum Testamentum Sinaiticum, lxxiv-lxxvi, who assigns C ${ }^{\mathrm{c}}$, as he does not distinguish between $\mathrm{C}^{\mathrm{c}}$ and $\mathrm{C}^{\mathrm{c} *}$ correctors. CSP's more precise assignment follows Milne and Skeat, Scribes and Correctors, 49-50.
} 
than their exemplars, resulting in coincidental agreements.

Let us first consider the six $\mathrm{C}^{\mathrm{c*}}$ corrections. In two cases $(16.18,19.13 \mathrm{a}), \mathrm{C}^{\mathrm{c*}}$ creates a singular reading. At 16.10, the corrected reading is weakly attested, and could also indicate the corrector's own judgement rather than his exemplar. In the remaining three instances $(11.4,14.8,18.7)$, both initial and corrected readings are relatively well-attested, the corrected readings agreeing, in each case, with $\mathfrak{M}^{\mathrm{A}}$. Clearly, the witness of Sinaiticus' $\mathrm{C}^{\mathrm{c*}}$ corrections must be weighed on a case-by-case basis and should only be cited with due caution. One must especially keep in mind that, as Milne and Skeat argued, this class of corrections are significantly later than, and most likely unrelated to, the remaining C-corrections. ${ }^{85}$

Secondly, and more importantly, we turn to the $35 \mathrm{C}^{\mathrm{a}}$ corrections. Although Schmid cites $\mathrm{S}^{\mathrm{a}}$ corrections throughout his analysis, he specifically discusses them only in relation to the Andreas text. It is all the more striking, therefore, that only six of them $(4.1,7.9,9.12,13.6,16.17,22.20)$ appear in his collation of Andreas. Taking all of Schmid's citations into account, however, we come to more robust (and certainly more revealing) figures. In fact, only four corrections $\left(4 \cdot 5^{-6,13.6,16.17}\right.$, 22.20) cited by Schmid accord (virtually) solely with $\mathfrak{M}^{\mathrm{A}}$, and, at five further places (1.19, 4.1, 7.9, $9.12,11.8), \mathfrak{M}^{A}$ is joined by some of the witnesses to older text-forms.$^{86}$ Nine of these corrections, then, exhibit some affinity with the Andreas tradition; in at least four cases (4.1, 7.9, 9.12, 13.6), though, it is possible that the agreement is non-genetic. One correction is supported by the $\mathfrak{M}^{\mathrm{K}}$ tradition (17.6) - again, virtually solely, and possibly non-genetically - and, in three further cases

\footnotetext{
${ }^{85}$ Milne and Skeat, Scribes and Correctors, $5^{0 .}$

${ }^{86}$ At 4.1, $\mathfrak{M}^{\mathrm{A}}$ is joined by 2846 which was not available to Schmid at the time of his writing and, at $7 \cdot 9$, we have the support of 2053 with the text of Oecumenius. The support of 2053 at 13.6 is only partial, as the reading does not appear in the commentary, and so the reading appears in the former group. The support of these minuscules with an early text is so treated throughout the following discussion.
} 
(14.8-9a, 19.13b, 20.8), $\mathfrak{M}^{\mathrm{K}}$ is joined by some of the earlier witnesses. Both later textual streams join together at three places $(1.18,20.12,21.20)$, and at five further places $(3.5,11.3,11.16 a, 14.8-9 b, 19.6)$ with some earlier support. In eight cases (4.2, 6.4, 9.13b, 11.16b, 14.8-9c, 21.6, 21.18, 21.27), the corrected readings are supported by early witnesses, but as many as five of these agreements $(4.2,6.4$, 11.16b, 14.8-9c, 21.6) could be non-genetic. Notably, five corrections (2.20, 9.13a, 14.3, 18.8, 20.9-10) cited by Schmid have rather scant support and are probably non-genetic. And at 11.9, $\mathrm{C}^{\mathrm{a}}$ attempted a shift that he abandoned in the process, reverting the reading back to its original form.

Since the above figures apply solely to Schmid's selection of readings rather than to the whole of $C^{\text {as }}$ s correcting activity in Revelation, a summary of textual affinities of all the $C^{\text {a }}$ corrections in Revelation is in order. Setting $C^{a}$ s retouchings of scribal corrections and other textually irrelevant interventions aside,${ }^{87}$ we come to the following figures: Eight corrected readings $\left(1.17 \mathrm{~b}, 2.13,4.5^{-6}\right.$, $6.15,13.6 \mathrm{~b}, 16.17,17.8,22.2 \mathrm{ob})$ are peculiar to $\mathfrak{M}^{\mathrm{A}}$, and at 16 further places $\left(1.19,1.20,2.10 \mathrm{a}, 4.1,4.3^{-4}\right.$, 4.8c, 7.9b, 7.9c, 9.12b, 10.1, 11.2d, 11.8b, 14.13, 19.1, 20.12a, 22.18) $\mathfrak{M}^{\mathrm{A}}$ is joined by some of the older witnesses. Two corrected readings $(17.6,21.14)$ are supported by $\mathfrak{M}^{\mathrm{K}}$, and in eight cases $(1.8 \mathrm{~b}, 15.7,16.14$, $18.13 \mathrm{a}, 19.9 \mathrm{~b}, 19.13,20.8 \mathrm{~b}, 22.3 \mathrm{~b}) \mathfrak{M}^{\mathrm{K}}$ is joined by some of the earlier witnesses. In four cases $(1.18 \mathrm{~b}$, $17 \cdot 3,20.12 c, 21.20 c)$, the corrected reading is supported by both $\mathfrak{M}^{A}$ and $\mathfrak{M}^{\mathrm{K}}$. More significantly, both later streams are joined by earlier witnesses at 169 corrected readings $(1.1 \mathrm{a}, 1.1 \mathrm{~b}, 1.5 \mathrm{a}, 1.5 \mathrm{~b}, 1.7 \mathrm{a}, 1.7 \mathrm{~b}$, 1.7c, 1.8a, 1.9, 1.11a, 1.11b, 1.11c, 1.13, 1.16, 1.17c, 1.18a, 2.1, 2.9, 2.10b, 2.14a, 2.17, 2.19a, 2.20b, 2.20d, 2.21, 2.23, 2.24a, 2.26a, 2.26b, 3.2, 3.3, 3.5, 3.12a, 3.12b, 3.14a, 3.14b, 3.15, 3.16a, 3.16b, 3.17, 4.8a, 4.8b, 4.8d, 4.9, 4.10, 5.1a, 5.4a, 5.4b, 5.7, 5.8, 5.13b, 6.1, 6.9a, 6.9b, 6.9c, 6.11, 6.12, 6.14, 6.16, 7.2a, 7.2b, 7.9a, 7.10a, 7.10c, 7.11,

\footnotetext{
${ }^{87}$ I also exclude four corrected itacisms at 1.17a, 2.16, 14.11, 20.3 and ten reverted corrections at 2.14b, 3.12d, 9.4, 9.18, $10.2,11.9 \mathrm{a}, 15.3 \mathrm{~b}, 16.16,18.13 \mathrm{~b}, 19.15$.
} 
7.12, 7.17, 8.6, 9.1, 9.2, 9.2-3, 10.3a, 10.3b, 10.3c, 10.6a, 10.6b, 10.8, 11.1, 11.2a, 11.2b, 11.2c, 11.2e, 11.3, 11.4, 11.5, 11.6, 11.7, 11.8c, 11.10, 11.11, 11.15, 11.16a, 11.17a, 11.7b, 11.18, 11.19a, 11.9b, 12.1, 12.4, 12.6, 12.14b, 12.14c, 13.1, 13.2, 13.6a, 13.7, 13.8a, 13.16a, 13.16c, 13.17, 14.1, 14.2, 14.3b, 14.4, 14.6, 14.14, 14.18, 14.20, 15.3a, 16.2a, 16.13a, 16.13b, 16.15, 16.18a, 16.18b, 16.19, 17.2, 17.4, 17.9, 17.12a, 17.12b, 17.15, 17.17a, 18.8a, 18.9a, 18.9b, 18.14, 18.16, 18.23, 19.2, 19.4, 19.5, 19.6, 19.7b, 19.9a, 19.9c, 19.10, 19.19, 19.20, 20.1b, 20.1c, 20.8a, 20.15, 21.3a, 21.3b, 21.3c, 21.4a, 21.4b, 21.6b, 21.20a, 21.21a, 21.21b, 21.21c, 21.25, 22.3a, 22.6, 22.12, 22.14, 22.20a). Finally, 26 singular (1.6a, 2.19b, 2.20c, 2.24b, 7.10b, 7.15, 8.4, 10.9, 11.8a, 12.11, 12.13a, 12.13b, 17.10, 17.17b, 19.12a, 19.12b, 20.12b, 21.6a, 21.9, 21.12, 21.13a, 21.13b, 21.20b, 21.21d, 22.2, 22.7) and 28 weakly attested (2.14c, 2.20a, 2.22, 2.24c, 3.7, 3.12c, 5.1b, 6.6, 7.13, 8.11a, $9.13{ }^{88} 9.14,9.19,11.9 \mathrm{~b}, 11.14,13.5,13.8 \mathrm{~b}, 13.8 \mathrm{c}, 13.16 \mathrm{~b}$, 14.3a, 14.8-9, 18.8b, 19.9d, 20.1a, 20.9-10, 21.15, 21.16, 21.23) readings were found amongst $C^{\text {as }}$ corrections. Besides several reverted corrections, retouchings of nomina sacra, and other textually insignificant interventions whose origin does not require an exemplar, these readings furnish us with the best evidence that, occasionally, $\mathrm{C}^{\mathrm{a}}$ made corrections irrespective of his exemplar. Naturally, at some places, we may have imperfectly executed corrections or inherited singulars, but this type of explanation can scarcely account for all such cases.

Most of the 261 above-listed corrections rectify what were most likely scribal errors, since, in 137 instances, the initial reading appears to be singular and, in 67 instances, the initial reading is weakly attested. Yet this does not warrant exclusion of such variation-units from consideration, as $\mathrm{C}^{\mathrm{a}}$, working some two centuries after the production of Sinaiticus, would have have used a different Vorlage, from which follows that all of his resultant readings are relevant for understanding

\footnotetext{
${ }^{88}$ As noted in $\mathrm{n} .41$ above, Schmid artificial divides the single corrections at 9.13 and $14.8-9$ into three distinct variation-units. As seems clear from their classification under weakly attested readings, taking the corrections in their entirety may alter their textual character rather significantly.
} 
textual affinities of that Vorlage. ${ }^{89}$

As seems obvious from this brief summary, the textual direction of $\mathrm{C}^{\mathrm{a}}$ corrections is far from straightforward. Apart from the most obvious problem of non-genetic origin in some cases, unique agreements with Andreas are, in fact, not very numerous. Indeed, one fails to observe a marked tendency towards an Andreas-type text. ${ }^{90}$ Given the further 10 corrections agreeing with $\mathfrak{M}^{\mathrm{K}}$ and 176 corrections agreeing with both $\mathfrak{M}^{\mathrm{A}}$ and $\mathfrak{M}^{\mathrm{K}}$ (and very often also with the rest of the tradition), it seems more likely these $\mathrm{C}^{\mathrm{a}}$ corrections reflect - and, perhaps, are themselves part of - a development of the text of Revelation that we see realised more fully in later text-forms now known as Koine and Andreas (especially the latter). ${ }^{91}$ This is unsurprising, as Schmid himself did not construe Koine and Andreas as completely independent of each other, as both share numerous "Korrekturen" to the more ancient text of Revelation..$^{92}$ This argument gains in plausibility when we take into account the fact that $\mathrm{C}^{\mathrm{a}}$ corrections may well have predated the composition of Andrew's commentary by almost a century, at which time the Andreas text-form was most likely still evolving. If this suspicion proves to be correct - and only further study can determine that - even

\footnotetext{
${ }^{89}$ Pace Bousset, "Textkritik," 42.

${ }^{90}$ Cf. Schmid's ( Studien, 2.127) reference to Bousset, “Textkritik," 42, quoted above. As it is, even Bousset's list of $\aleph^{c}$ readings agreeing with $\mathfrak{M}^{\mathrm{A}}$ (his $\mathrm{K}$ ) is not without problems. In fact, only 14 of the 28 readings he lists $(1.20,2.13,4.1,4.5$, $6.15,7.9 \mathrm{~b}, 7.9 \mathrm{c}, 9.12 \mathrm{~b}, 10.1,11.8 \mathrm{~b}, 13.6 \mathrm{~b}, 16.17,17.8,22.20 \mathrm{~b}$ ) are clearly readings of $\mathfrak{M}^{\mathrm{A}}$ (at 1.20, 7.9c, 9.12b, 11.8b, and 13.6b with earlier support). At 1.6a, 9.14, 21.9, and 22.2, the resultant reading is singular and seems better explained as $C^{\text {as }}$ s grammatical improvement rather than his failure to transmit the Vorlage. Further, 3.5 and 21.20c agree with both $\mathfrak{M}^{\mathrm{A}}$ and $\mathfrak{M}^{\mathrm{K}}$; $18.8 \mathrm{~b}$ is supported by $1250424616204821862428 \mathrm{al} ; 20.9$ is supported by $\mathrm{P} 2053^{\mathrm{txt}} 2846$; and 21.23 is supported by $051^{\mathrm{s}} 20302377 p c$. Bousset's collation appears to be incorrect at 2.20c, 6.9, 7.10b, 8.11a, and 10.2. Cf. Hernández Jr., "The Legacy of Wilhelm Bousset," 23-25.

${ }^{91}$ On the role of manuscript corrections in textual transmission, see Royse, Scribal Habits, 75-76; M.W. Holmes, "Working with an Open Textual Tradition: Challenges in Theory and Practice," in The Textual History of the Greek New Testament: Changing Views in Contemporary Research, ed. K. Wachtel and M. W. Holmes (SBL Text-Critical Studies 8; Atlanta: Society of Biblical Literature, 2011), 69.

${ }^{92}$ Schmid, Studien, 2.146. Ironically, though the text used in Andrew's commentary is replete with grammatical improvements, Andrew himself condemns scribes who atticised the text of Revelation. See J. Hernández, Jr., "The Relevance of Andrew of Caesarea for New Testament Textual Criticism," JBL 130 (2011), 188-191, 194-195.
} 
Schmid's notion of the recensional nature of the Andreas text may be called to question. For Schmid construed the Andreas text as "eine Rezension im eigentlichen Sinne, das Werk eines Mannes ... der den Text durch alle Kapitel durchkorrigiert hat." ${ }^{\text {93 }}$ Nevertheless, we posses no documentary evidence for such a thoroughgoing recension that would predate the composition of Andreas' commentary - and nor did Schmid, as he did not base his recensional theories on a purely documentary basis, but rather on a large number of "Korrekturen" that were peculiar to the Andreas text. ${ }^{94}$ Thus, we may be on firmer ground in invoking E.C. Colwell's dictum that "[a] texttype is a process, not the work of one hand. ${ }^{95}$ Rather than an incomplete witness to an already completed recension, then, these $\mathrm{C}^{\mathrm{a}}$ corrections could possibly be a witness to such a process with respect to the text of Andreas. The notion of a lengthier, slower process of correction and revision, whereby older readings are mixed with the secondary readings, could thus account for the presence of older readings in later text-forms. ${ }^{96}$ One may well wonder whether these "Korrekturen" could not have, in some cases at least, originated as manuscript corrections proper. $^{97}$

An inevitable conclusion of the present discussion is that $\mathrm{C}^{\mathrm{a}}$ corrections, when properly identified and understood, are not what either Schmid or Bousset held them to be. For one thing, as Hernández has demonstrated, they significantly postdate Sinaiticus' production, and thus cannot be used as the fourth-century evidence for the Andreas text. Secondly, given the textual affinities

\footnotetext{
${ }^{93}$ Schmid, Studien, 2.53. Schmid also notes a possibility that a small portion of improvements could have been inherited.

${ }^{94}$ See Schmid, Studien, $2.52^{-53}$. The $S^{\text {a }}$ corrections assisted Schmid in tracing the Andreas text to the fourth century.

${ }^{95}$ E.C. Colwell, "Method in Establishing the Nature of Text-Types of New Testament Manuscripts," in Studies in Methodology in Textual Criticism of the New Testament, ed. E. C. Colwell (Leiden: Brill, 1969), 53.

${ }^{96}$ So Colwell, “Text-Types," 52. See also Hernández, "Creation,” 107-108, 114.

${ }^{97}$ Cf. Colwell, "Text-Types," 52-53: "Revision almost universally proceeded on a documentary basis. Manuscripts from outside the text-type were used to revise it. This opened a door through which Ur-text readings could be added just as surely as it opened the door to alien corrections and corruptions."
} 
of $\mathrm{C}^{\mathrm{a}}$ corrections outlined above, Bousset's claim that the corrector used a Vorlage with his $K$ text akin to that of the text of Revelation in Andreas' commentary - seems problematic as well. What seems more likely is that our corrections may rather prove to be an important, if indirect, witness to the development of the later forms of the text of Revelation. 